The experiments wore supported by the Biomagnetic Research Foundation.

College of Pharmacy,

University of Illinois, Chicago.

'Barnothy, M. F., and Barnothy, J, M., Nature, 181, 1785 (1958).

"Barnothy, J. M., Barnothy, M. F., and Boszormeny-Nagy, I., Nature,

3 Barnothy, J. M., Nature, 200, 86 (1963).

\section{Distribution of Cyanole and Neutral Red in the Giant Axon of the Squid}

PRevious work on the permeability of frog muscles ${ }^{1}$ and giant axons of Cephalopoda $a^{2,3}$ to vital dyes has shown that basic and acid dyes rapidly penetrate tho cell and its intracellular content may bo less or greater than in the medium, depending on the outside concentration and typo of the dye. For ginnt axons in tho steady state the coeffi. cient of distribution $\left(Q=\frac{C_{\text {in }}}{C_{\text {out }}}\right.$, whore $C_{\text {in }}$ and $C_{\text {out }}$ represent respectively intra- and extra-collular concentra. tion) for the acid dye (cyanole) was found to bo 0.12 with the external dye concentration varying from $0 \cdot l$ to $1 \cdot 0$ per cont (rof. 3). At the same timo the coefficiont of distribution of the basic dye (noutral red) changed from 5.5 to 0.65 on a corresponding increase in $C_{\text {out }}$ from 0.004 to $0 \cdot 16$ per eont (ref. 2 ).

The purposo of the work rocorded here was to investigate the $Q$ values for axoplasm itself and compare them with the previously obtained values for the whole axons. Therefore the content of the dye was determined both in the whole axons and pipetted axoplasm.

Exporiments wero porformed on tho axons of Loligo sp., 200-300 $\mu$ in diamoter. Isolated axons were soaked in cyanole or noutral red solution for $20 \mathrm{~min}$. As has already boon shown ${ }^{2}$, a period of $10-20 \mathrm{~min}$ is onough to reach oquilibrium. Then the axons wero washed up (5-10 sec) in sea-water and blottod. The amount of dyo in ethanol acid extracts of axons was determined with the aid of a visual microcolorimeter. For measuring the dye content in axoplasm the stained fibres were cut; axoplasm was then extracted with a micropipette and also transferred to the ethanol acid mixture. The amount of dye was calculated per unit of the fibre or axoplasm volume.

The results obtained are given in Table 1.

\begin{tabular}{|c|c|c|c|c|}
\hline \multicolumn{5}{|c|}{ Tablc 1} \\
\hline Dye & $\begin{array}{l}\text { Concentration } \\
\text { in the axon } \\
\text { (Cin) (mg \%) }\end{array}$ & $\begin{array}{c}\text { Concentration } \\
\text { in the axoplasm } \\
\text { (Cap) (mg \%) }\end{array}$ & $\frac{C_{\text {in }}}{C_{\text {ap }}}$ & $\frac{C_{\text {ap }}}{C_{\text {out }}}$ \\
\hline $\begin{array}{l}1 \% \text { Cyanole } \\
0.01 \% \text { Neutral red }\end{array}$ & $\begin{array}{c}120 \pm 5 \\
63 \pm 5\end{array}$ & $\begin{array}{l}82 \pm 16 \\
35 \pm 5\end{array}$ & $\begin{array}{l}1.46 \\
1.80\end{array}$ & $\begin{array}{l}0.082 \\
3.5\end{array}$ \\
\hline
\end{tabular}

As can bo seen, an increase as well as a decrease in the bulk dye concentration in axons compared with the medium dopends on the encentration of dye in the axoplasm. In aecordance with the provious studies ${ }^{1-2}$, the observed distribution of dyes can bo considered as a result of two factors: (1) docreasod solubility of protoplasm for tho substances with the sire of molecules as big as that of dyes; (2) adsorption or chemical binding of dyes by protoplasmic components. Hence the total content of the dye in axoplasm may be exprossed with the formula given by Troshin ${ }^{1}: C_{\text {in }}=K \times O_{\text {out }}+A$, whore $K$ is the solubility coefficient of the dye in protoplasm as compared with the medium; thus $K \times C_{\text {out }}$ gives the dissolved portion of the dye; $A$ is adsorbed or chemically bound dye por unit volumo.

The analysis of cyanole distribution shows ${ }^{3}$ that, by varying $C_{\text {out }}, A$ is practically equal to 0 , whereas for neutral red the bound dye fraction is big enough ${ }^{2}$. This is also confirmed by special experiments made to investigate the efflux of dyes from axons. When cyanole-stained axon is put in sea-water, the dyo loaves the fibre very soon, and the axon becomos completely colourless within $5 \mathrm{~min}$. Similar exporiments with neutral red show that tho colour is retained for a much longer time. Thus, after 30 min soaking in sea-water, the neutral red concentration in axoplasm was still $14 \pm 4 \mathrm{mg}$ por cent, that is, 40 per cent of the dye still remained in the axon. 'The same slow efflux of cyanole was observed only in killed or damaged axons.

'The expcriments show that in the case of cyanole the dissolved fraction of the dye gave only $0.12 \times C_{\text {out }}$ while for neutral red $^{2} K=0.25$.

The values obtained for $K$, considerably less than unity, probably indicate that not the whole protoplasmic water is available for the substances with the sizo of molecules more than $3 \AA$. In any ovont, a steady-state distribution of dyes with the $Q$ value less than unity cannot bo explained by the Donnan effect ${ }^{2,8}$; analogous $Q$ values were obtained for the distribution of non-eloctrolytes in muscles $\mathbb{S}^{1,4,5}$.

Thus we can concludo that the difference in the steady. state concentration of the dye in axon as compared with medium (decrease as well as increase) may be explained by the specific properties of axoplasm, and for this explanation no membrane pump hypothesis is needed.

We thank the Science Committee of the Peoples Ropublic of Viet Nam where the work was performed, and also Dr. Vū Dinh Tân for assistanco.

\section{N. N. NIKoLSKY}

S. A. KROLENKO

Institute of Cytology,

Acaderny of Sciences of the U.S.S.R., Loningrad.

${ }^{2}$ Troshin, A. S., Simp. CSAV, Praha, 45 (1960).

${ }^{2}$ Vereninov, A. A., Nikolsky, N. N., and Rosental, D. L., Tsitologiya (U.S.S.R.), 4, 171 (1962).

${ }^{3}$ Krolenko, S. A., and Nikolsky, N. N., Tritologiya (U.S.S.R.), 5, 414 (1963).

4 Bozler, E., Amer. J. Physiol., 200, 651 (1061).

'Norman, D., MenozzI, P., Reid, D., Lester, (ł., and Hechter, O., J. Gen. Physiol., 42, 6, 1277 (1959).

\section{Dispersal Rates of Several Ungulates introduced into New Zealand}

BETWEEN 1851 and 1923 several species of ungulates were introduced into New Zealand. During this period there were also many liberations into unstocked areas of game animals takon from recently established populations. Dates and localities of liborations have been summarized ${ }^{1,2}$ and the present or recent distributions of most species havo been published ${ }^{2-5}$.

Tablo 1 gives mean rates of dispersal over periods exceeding 50 years, taken from populations that were continuously expanding their ranges over those periods. The rate is measured as the distaneo botween the point of liboration and the farthest known breeding colony, divided by the number of years that have elapsed.

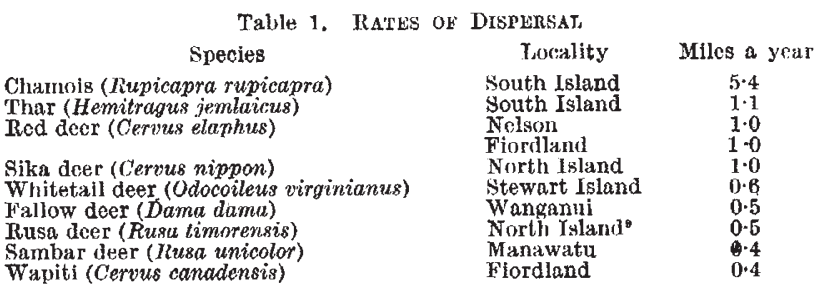

There have been more than 100 liberations of rod doer ${ }^{\circ}$ and the populations doveloped from these have coalesced so that the pattern of dispersal is now completely obscured. But the distributions had been roughly mapped bofore this occurred?, and a rate of dispersal can be calculated for the Nolson herd between 1851 and 1924. This is probably one of the few red door herds the distribution of which was not strongly modified by secondary liberations near its periphery. The rate of spread in Fiordland 